\title{
Etnografia e letramento: novos desafios para velhas memórias
}

\author{
Lucrécio Araújo de Sá Júnior (SÁ JÚNIOR, Lucrécio A. de) \\ Professor Doutor, Instituto Federal do Rio Grande do Norte - IFRN, Campus João \\ Câmara \\ lucrecio.sa@gmail.com
}

Beliza Áurea de Arruda Mello (MELLO, Beliza A. de A.)

Professora Doutora, Universidade Federal da Paraíba - UFPB

belizmel@uol.com.br

\section{Resumo}

No campo da educação de adultos, existe muito debate sobre como os programas de alfabetização podem melhor servir os alunos. Acreditamos que a alfabetização de adultos não deve ser limitada a ensinar habilidades específicas, mas deve contextualizar instrução dentro de um quadro de ativismo social e de transformação. Este artigo considera o papel das tradições orais para o processo de letramento, sob a contribuição da etnografia e o uso empírico desta na sala de aula. Este debate se centra numa abordagem teórica sobre os estudos de letramento para ilustrar o poder da etnografia como experiência contextualizada. Os aspectos da cultura oral que se mantêm em uma sociedade podem ser concebidos em torno das origens, necessidades e interesses dos alunos e podem incentivar uma "dialógica" onde os alunos sejam capazes de utilizar a alfabetização desenvolvendo habilidades para analisar criticamente o seu lugar na sociedade e compreender como certas pressuposições e percepções culturais têm afetado a eles e suas famílias.

Palavras-chave: letramento, memória, oralidade, educação de adultos, etnografia, cultura.

\begin{abstract}
In the field of adult education, there is much discussion on how literacy programs can best serve students. Adult literacy programs should not be confined to teaching specific literacy skills but rather should contextualize instruction within a framework of social activism and societal transformation. This article looks at the role of oral traditions in the literacy process, with the empirical use of ethnography in the classroom. This discussion is based on theory in literacy studies to illustrate the power of ethnography to contextualize experiences. Those aspects of oral culture that remain or persist in a society can be designed around the backgrounds, needs, and interests of students, which can in turn encourage a "dialogic" where students are able to use their developing literacy skills to critically analyze their place in society and understand how certain cultural assumptions and biases have put them and their families at risk.
\end{abstract}

Keywords: literacy, memory, orality, adult education, ethnography, culture. 


\section{Introdução ao tema}

Neste trabalho busco uma abordagem que se refere diretamente à educação de adultos com a idade já avançada, socialmente concebidos como economicamente inativos. Seguindo os indicadores educacionais do Brasil o número de analfabetos com mais de 50 anos chega a 31,5\%. No entanto programas do Ministério da Educação como EJA visam apenas combater o analfabetismo entre jovens de 15 a 29 anos. Por isso, para este estudo uma das perguntas centrais é: numa sociedade para que servem os idosos? Para lembrar, lembrar muito e lembrar bem. Esta é uma conclusão simples que pode ser tirada da leitura da obra Memória \& sociedade: lembrança de velhos, da historiadora da USP Ecléa Bosi (2003).

A relação estreita entre memória e trabalho mostrada por Bosi, feita pela análise das vidas de seus personagens, é uma constatação de que a função social da velhice, nem sempre é reconhecida, e dessa forma não deveria ser perdida. Os idosos são para a cultura "agentes efetivos". Em qualquer sociedade estes desenvolvem um papel preponderante, enquanto lembram eles ainda "fazem". Por significativos motivos, em toda sociedade, existem textos que são conservados em memória. O objetivo deste trabalho é levantar discussão sobre a possibilidade de uso desses textos na Escola.

Ao desenvolver uma filosofia da educação voltada para autonomia do ser humano, Paulo Freire (1998) enfocou a importância do ensino contextualizado. Considerando esta visão, pretendo identificar como textos orais da cultura popular podem contribuir no processo de ensino-aprendizagem da alfabetização de adultos idosos.

Tradições orais, elementos da memória e do imaginário têm sua importância em uma sociedade, e podem ser entendidas como a síntese dos fatos mais relevantes a um conjunto de cidadãos. Assim como a educação, as tradições são produzidas a partir das bases existenciais de cada indivíduo, constituída na coletividade cotidianamente. Muitos textos orais das tradições e manifestações da cultura popular são transmitidos e mantidos pela memória coletiva. Aqui, articula-se a seguinte questão: é possível o uso desses textos na escola? Como torná-los presentes na metodologia de ensinoaprendizagem? Creio que respostas efetivas para estas questões poderão tangenciar novas práticas de ensino-aprendizagem nas escolas e permitir a existência de competências múltiplas de aquisição da leitura/escrita. Dessa forma, pretendo discutir neste ensaio o conceito de letramento tendo como base textos orais, cuja finalidade específica em tempo e espaço determinados, conservam-se em memória. Para isso abordo inicialmente a conceito da Etnografia da sala de aula, atualmente bastante discutido nos meios acadêmicos, para em seguida propor a extensão dessa concepção, através dos Gêneros da literatura oral e tradicional. Como veremos, a Etnografia e seu uso na sala de aula poderão assumir amplos sentidos.

\section{Etnografia da sala de aula: observação participante}

Para Mattos (2001), a maior preocupação do trabalho etnográfico para uso na sala de aula é obter uma descrição densa, a mais completa possível, sobre o que um grupo particular de pessoas faz e o significado das perspectivas imediatas do que eles têm e do que eles fazem; esta descrição é sempre relacionada com a comparação etnológica em mente. Na concepção da autora, o objeto da etnografia é esse conjunto de 
significantes em termos dos quais os eventos, fatos, ações, e contextos, são produzidos, percebidos e interpretados, e sem os quais não existem como categorial cultural.

Primeiro, por preocupar-se com uma análise holística ou dialética da cultura, isto é, a cultura não é vista como um mero reflexo de forças estruturais da sociedade, mas como um sistema de significados mediadores entre as estruturas sociais e a ação humana; segundo, por introduzir os atores sociais com uma participação ativa e dinâmica no processo modificador das estruturas sociais. O "objeto" de pesquisa agora "sujeito" é considerado como "agência humana" imprescindível no ato de "fazer sentido" das contradições sociais; e terceiro, por revelar as relações e interações ocorridas no interior da escola, de forma a abrir a "caixa preta” do processo de escolarização. (MATTOS, 2001, p. 4)

Segundo Mattos, a etnografia sempre teve interesse na comparação etnológica e a maioria das pessoas que faz este trabalho hoje continua a utilizar este instrumento de análise. Nas palavras da autora, ao estudarmos uma vila, por exemplo, observaremos a vila toda; jovens, velhos, área urbana, rural, relações intergeracionais, relações de gênero, de classe - os fatos sociais que ocorrem neste contexto. Percebendo a etnografia como escrita do visível, Mattos propõe que

Nós não estamos interessados numa forma única de variação em relação ao total da variação humana, mas estamos também interessados em exaustivamente analisar qualquer forma de variação existente no grupo local. Se numa comunidade local existe mais de uma maneira de organização social do grupo, por exemplo, em relação à linguagem, classe social e gênero, nós sempre vamos querer descobrir todos os modos de agrupamento daquele grupo em particular. (MATTOS, 2001, p. 4)

Para Mattos, a descrição etnográfica pode ser utilizada como uma qualidade de observação, de sensibilidade ao outro, do conhecimento sobre o contexto estudado, da inteligência e da imaginação científica do etnógrafo. A microanálise etnográfica é um instrumento da etnografia, freqüentemente utilizada nos estudos da linguagem, e é caracterizada como: sociolingüística da comunicação, microanálise sociolingüística, sociolingüística interacional, análise de contexto, análise de discurso, análise da conversação. A autora ressalta que a etnografia em geral serve de "background" para a microetnografia. Como estudo de caso realizado, Mattos cita o exemplo de um teste sobre o turno de fala e os padrões culturais da fala, comparando culturalmente um grupo familiar de origem italiana com uma família americana. Neste caso após extensivo trabalho de observação participante, alguns segmentos de fala foram destacados para microanálise.

Na microanálise etnográfica fazem-se uso de aspectos para estudar a sala de aula observando por um longo período de tempo uma escola, uma sala de aula, um professor, para depois particularizar um processo interacional ou um fato que se considera microanaliticamente relevante. Isto é, destacando um fato que numa micro-dimensão representa o todo do processo estudado. Sob a perspectiva da etnografia de sala de aula se busca desvelar a cultura escolar, uma sala de aula em particular ou interações interpessoais desenvolvidas no âmbito escolar.

Para Mattos, a etnografia da sala de aula é também conhecida como pesquisa social, observação participante, pesquisa interpretativa, pesquisa analítica, pesquisa hermenêutica. Na opinião da autora, trabalho Etnográfico compreende o estudo pela observação direta num período de tempo para culminar no inventário das formas 
costumeiras de viver de um grupo particular de pessoas: um grupo de pessoas associadas de alguma maneira, uma unidade social representativa para estudo, seja ela formada por poucos ou muitos elementos. Por exemplo: uma vila, uma escola, um hospital, etc.

A etnografia estuda preponderantemente os padrões mais previsíveis do pensamento e comportamento humanos manifestos em sua rotina diária; estuda ainda os fatos e/ou eventos menos previsíveis ou manifestados particularmente em determinado contexto interativo entre as pessoas ou grupos. Em etnografia, holisticamente, nós observamos os modos como esses grupos sociais ou pessoas conduzem suas vidas com o objetivo de "revelar" o significado cotidiano, nos quais as pessoas agem. O objetivo é documentar, monitorar, encontrar o significado da ação. (MATTOS, 2001, p. 2)

A autora afirma que tanto a etnografia mais tradicional quanto a mais moderna envolvem longos períodos de observação, um a dois anos, preferencialmente. Este período se faz necessário para que o(a) pesquisador(a) possa entender e validar o significado das ações dos(as) participantes, de forma que este seja o mais representativo possível do significado que as próprias pessoas pesquisadas dariam a mesma ação, evento ou situação interpretada. De acordo com Mattos, a etnografia como abordagem de investigação científica traz algumas contribuições para o campo das pesquisas qualitativas que se interessam pelo estudo das desigualdades e exclusões sociais.

Ora, muito se tem debatido nos meios acadêmicos o conceito de Etnografia da sala de aula. A Etnografia da sala de aula busca tornar o processo de aquisição da leitura/escrita mais bem elaborado, na perspectiva de definir e apreender comportamentos, atitudes, idéias e valores. O trabalho etnográfico não deve se limitar apenas em observar as condições socioeconômicas, culturais e políticas que influenciam no comportamento individual e coletivo do educando em questão. Os objetivos dos estudos que discutem atualmente o uso da Etnografia para a sala de aula são:

- Investigar como as condições socioeconômicas influenciam o letramento de um educando;

- Identificar que influências o contexto sociocultural exerce no letramento de uma pessoa;

- Analisar de que maneira a práxis de um professor contribui para o letramento do aluno.

Todos os aspectos da vida do ser humano estão intimamente interligados, portanto, sem considerar a identidade coletiva e a memória social, esses objetivos revelam uma clara limitação pragmática. Na perspectiva de Letramento, a Etnografia pode ser explorada para a inserção e reconhecimento de textos orais que advém dos aspectos sociais, históricos e culturais. É possível focar o ensino-aprendizagem na oralidade, tendo como pressuposto básico o conhecimento pré-existente do educando. A oralidade é uma prática social interativa para fins de comunicação e se apresenta segundo Marcuschi (2005, p. 25) "sob variadas formas ou gêneros textuais fundados na realidade sonora, ela vai desde uma realização mais informal à mais formal nos mais variados contextos de uso”. 


\section{Etnografia na sala de aula: na perspectiva das tradições orais}

Nas tradições populares, a oralidade revela um sistema simbólico de relações. A cultura popular traduz a superposição entre as duas modalidades da língua e não pode ser descontextualizada do tempo / espaço em que se produz. Concebendo a memória humana como mecanismo cognitivo, o seu uso na sala de aula exige uma competência tripla, pois ela não deve ser vista apenas como um texto verbal, nem como uma mera transcrição escrita, mas um tipo de gênero literário, que surge do resultado da conjugação dessas duas materialidades citadas. Dessa maneira, sob a perspectiva do 'modelo autônomo do letramento', a cultura popular poderá fazer uso dos atributos naturalizados da escrita, para tornar válidos os valores, as idéias, as relações coletivas. Assim, acredito que o uso do trabalho Etnográfico na perspectiva de Letramento deve ser melhor explorado, principalmente em se tratando da educação de adultos que transportam sua sabedoria através da memória e do imaginário popular.

Diante do exposto surge a pergunta: como isso pode ser possível? Ora, a sugestão aqui se justifica que se deve ter também a Etnografia na sala de aula e não apenas a Etnografia da sala de aula. Ou seja, fazer valer o uso da oralidade, para efetivamente alfabetizar/letrar usando textos que já existem previamente na memória do educando. Na cultura popular, evidenciam-se mitos, lendas, contos, provérbios, orações, maldições, encantamentos, etc. Podemos pensar na existência de textos orais para finalidades específicas em tempo e espaço determinados que constituem a cultura de um povo.

Acredito que o conceito e o uso da Etnografia na sala de aula pode e deve tomar um sentido mais amplo. Como já dito no trabalho Concepções de leitura: memória, oralidade, imaginário popular e letramento, ${ }^{1}$ as manifestações da cultura popular de cada região podem ser largamente viabilizadas para o trabalho didático-pedagógico em sala de aula. Para Geertz, praticar etnografia não é somente estabelecer relações, selecionar informantes, transcrever textos, levantar genealogias, mapear campos, manter um diário "o que define [a etnografia] é o tipo de esforço intelectual que ele representa: um risco elaborado para uma 'descrição densa'” (GEERTZ, 1989, p. 15).

Neste sentido, ao abordar o uso de material etnográfico na sala de aula, podemos nos referir a João David Pinto-Correia que identifica os tipos de textos conservados em memória nas múltiplas sociedades e propõe sua classificação e divisão em macroconjuntos, o que chama Gêneros da literatura oral e tradicional (1993). Para Pinto-Correia, a designação "Literatura Popular" corresponde a um conceito demasiado amplo e ambíguo. Mas, há a possibilidade, segundo o autor, de "arrumar os principais gêneros, segundo critérios coerentes” (PINTO-CORREIA, 1993, p. 69). Dessa maneira, seguindo a natureza das componentes discursivas e a sua funcionalidade temos (aqui sumariamente) a seguinte classificação dos três macroconjuntos:

- O primeiro diz respeito ao sentimento e ao afeto, à confessionalidade ou mesmo a práticas que têm a ver com crenças e supertições, é prático-religioso.

- O segundo é composto pelas composições narrativo-dramáticas. Na sua maior parte são em prosa, comunicam acções completas ou pequenos episódios narrativos, sempre completados pelo diálogo;

\footnotetext{
${ }^{1}$ Trabalho apresentado e publicado nos Anais do I Simpósio Nacional de Leitura, realizado na UFPB em 2007.
} 
- O terceiro, as composições dramáticas: Dizem respeito às peças e aos diálogos que muito abundam na vida quotidiana do povo. A designação mais habitual para estas composições é a de autos. Mas, há de se considerar a sua tipologia funcional. (PINTO-CORREIA, 1993, p. 65)

Cada um desses macroconjuntos aponta para um conteúdo específico e respectiva expressão. Para o autor, em cada um desses macroconjuntos temos de considerar duas vertentes: a religiosa e a profana. De maneira bem detalhada, PintoCorreia oferece subsídio para perceber, dominar e registrar o itinerário simbólico da memória e do imaginário social. Vale dizer, a arquitetura das finalidades e funcionalidades das tradições e dos processos sociais.

O trabalho de Pinto-Correia se fundamenta no campo da oralidade, expressões da cultura popular, dos costumes e tradições do povo. Todos os povos têm nas tradições orais a manifestação do seu imaginário. Ao abordarmos a oralidade seguindo as indicações do referido autor, não nos podemos esquecer de que lidamos com uma das modalidades do sistema lingüístico que, junto com a escrita formam o processo de construção do pensamento humano. Desse modo, Pinto-Correia nos dá indicação sobre a possibilidade de encontrar textos que surgem de uma narrativa, de uma estória, de uma cantiga, de uma reza ou de algumas situações corriqueiras da vida.

Considerando as indicações dos Gêneros da Literatura Oral, acredito que o educador/pesquisador poderá fazer uso dos atributos naturalizados dos “textos” da cultura popular para tornar válidos os valores, as idéias, as relações advindas da memória e do imaginário. Há aí uma natureza mista entre o oral e o escrito, pois a cultura de um povo pode ser entendida como a síntese dos fatos mais relevantes a um conjunto de cidadãos, refere-se a valores socialmente instituídos e compartilhados, dos quais todos tomam parte.

Dessa forma, o conceito de letramento precisa ser discutido dentro das práticas sócio-culturais que circulam em uma sociedade, utilizando os diversos meios de expressão textual em memória presentes na cultura popular. Considerar a oralidade popular, o imaginário, a memória como possibilidade de um novo enfoque para a educação, é considerar uma alternativa diferenciada do trabalho etnográfico no fazer do ensino-aprendizagem. Ao fazermos uso de textos orais para o processo de letramento podemos estar:

- dando ênfase a uma análise holística ou dialética da cultura entendida;

- introduzir os atores sociais com uma participação ativa e dinâmica e modificadora das estruturas sociais;

- preocupar-se em revelar as relações e interações significativas de modo a desenvolver a reflexividade sobre a ação identitária do grupo social.

Ao se referir à cultura popular como mecanismo alternativo para contribuir no processo pedagógico em sala de aula, enfocando o processo de letramento, o educador ao mesmo tempo em que trabalha os conteúdos referentes ao processo de ensino, pode estar provocando o reconhecimento da identidade e dos valores histórico-cultural do educando. Essa prática de ensino-aprendizagem poderá enfraquecer a marginalização das culturas locais que, na observação de Ecléa Bosi (2003), atualmente estão cada vez mais encobertas pela cultura de massa. 
Ao trabalhar a cultura popular como mediadora no processo educativo de letramento, é possível desenvolver alguns sentidos ocultados pelo não reconhecimento das identidades culturais. Educar a partir da cultura significa desenvolver competências que consistem em atitudes e habilidades individuais e coletivas apresentadas como a consciência crítica, imaginação, criatividade, expressão e comunicação.

Trabalhar com textos em memória não é o mesmo que fazer uso de livros e coleções didáticas impressas, como no caso do Cordel que já ocupa atualmente grandes espaços nas salas de aula. Este material etnográfico a que se refere este trabalho se constitui de textos híbridos para um dado povo em particular, ou seja, textos que constituem práticas populares efetivamente em uso para cada comunidade específica, nas quais os sujeitos sociais estão inseridos. Estas práticas variam de acordo com o tempo e o lugar, e não são as mesmas para cada povo.

Poetas populares, compositores, artistas e “intérpretes" acabam por produzir textos orais que servem à vida social, seja na dimensão religiosa ou profana. Na sociedade, estes sujeitos estão ‘jogando' com a voz, estão “manipulando” textos, revelando sentidos, estruturando seu discurso sobre o mundo através da capacidade criativa e poética da linguagem enlaçada com as estruturas antropológicas do imaginário e da memória.

$\mathrm{Na}$ busca de entender os usos e o significado desses textos, um ponto a ser destacado nesse método de análise é o papel do contexto no exame destas expressões. O contexto indica precisamente que a linguagem dos textos orais não é (e não deve ser) examinada em abstrato, mas sempre em relação a uma situação real em que se faz sentido (ou não) usar certas expressões. As expressões lingüísticas têm significado diversos nos diferentes jogos de linguagem e são formações complexas da ação do ser humano no mundo. Essas expressões possuem uma "gramática" encontrada nesses jogos de linguagem; isto é, essas atividades, compreendendo um jogo de linguagem, obedecem regras. $\mathrm{O}$ ato de cantar benditos, por exemplo, está engajado em práticas sociais estabelecidas e compartilhadas sob a égide de critérios determinados para sua realização numa dada sociedade. As situações de enunciação desses textos são, portanto, habilidades adquiridas em um processo de memórias, atualizadas e resignificadas, diacrônica e sincronicamente. Daí ser também necessário interpretar as estruturas do imaginário na experiência diária para se compreender como os textos orais podem ser trabalhados na sala de aula de modo significativo capaz de aprimorar competências e habilidades referentes à vivência individual/coletiva e desenvolver o senso crítico relativos às dimensões da organização da sociedade, os modos de produção, a divisão social do trabalho, o sistema de poder e as instituições relacionadas a esta estrutura.

\section{Considerações finais}

As tradições orais se constituem de textos discursivos dos quais a escrita pode surgir como arquivamento estratégico, o patrimônio imaterial pode contribuir na perspectiva pedagógica do letramento. Estender o conceito de letramento para além da leitura e escrita é o ponto principal deste trabalho, pois além de saber ler e escrever, e ter estas práticas como presença cotidiana, é preciso que os sujeitos sociais, enquanto educandos, possam ter o conhecimento dos valores intrínsecos da cultura em que estão inseridos.

A memória e o imaginário revelam epistemologicamente cada atitude. A Etnografia deve abordar as tradições que correm de boca em boca, com algumas ou com 
muitas modificações. E, também que fazem um acréscimo ocasionalmente nas performances culturais (cf. ZUMTHOR, 1997). Existem na memória coletiva textos que se conservam mais acentuadamente de acordo com determinadas circunstâncias. A proposta de letrar através destes textos poderá adentrar no campo da lingüística, para se fazer conhecer os valores da linguagem, tanto a norma culta quanto da fala não-oficial; no campo da história e da antropologia, a etnografia pode auxiliar no sentido de procurar entender as origens, a identidade e os valores; no campo da literatura e das artes, poderá servir para mostrar a oposição e semelhança entre o popular e o erudito; no campo político-ideológico poderá ocasionar uma crítica à cultura emergente de massa. Um trabalho efetivo com a memória em sala de aula poderá auxiliar a consciência essencial das tradições populares.

O processo de ensino e aprendizagem por meio da cultura popular poderá permitir ao educando expressar suas concepções de mundo utilizando-se dos diversos meios da expressão literária oral. Considerar a oralidade, o imaginário, a memória como possibilidade de um novo enfoque para a educação é considerar uma alternativa diferenciada para o processo de aquisição da leitura e escrita. Portanto, ao mesmo tempo em que se trabalham os conteúdos referentes ao processo de alfabetização, se realiza o registro das estórias, mitos, lendas, que fazem parte do processo da formação históricocultural de um povo. O que estamos percebendo ao longo dos tempos é a marginalização das culturas locais, por sua vez, a não transmissão de tradições existentes, ocasionando a dissipação das manifestações culturais que cada vez mais são encobertas pela cultura de massa.

Ao trabalhar a cultura popular como mediadora no processo educativo, além de valorizar a cultura popular, o educador estará desenvolvendo alguns sentidos ocultados pelo que se denomina "repressão" educativa, que consiste em atitudes e habilidades individuais apresentadas como a consciência crítica, imaginação, criatividade, expressão e comunicação, podada institucionalmente pelos programas curriculares das escolas. No âmbito do exercício pedagógico, o uso das tradições orais poderá possibilitar e viabilizar uma aprendizagem de forma prazerosa, produzindo novas estratégias que serão utilizadas como unidade de ensino interdisciplinar, levando o educando a refletir sobre a importância de aprender a escrever usando o conhecimento que possui, da memória. Partindo desse pressuposto, o texto produzido pelo aluno oralmente passa a conter sentidos a serem trabalhados como proposta pedagógica facilitadora no processo de formação do leitor-escritor auxiliando na construção da sua consciência metalingüística crítica. Zumthor (1997) defende que as tradições orais são fundamentais para a manutenção dos costumes e servem de alicerce para a constituição de uma sociedade. Nem toda memória é apenas história que passou.

\section{Referências}

BOSI, Ecléa. Memória \& sociedade: lembrança de velhos. São Paulo: EDUSP, 2003.

FREIRE, Paulo. Pedagogia da autonomia. Rio de Janeiro: Paz e Terra, 1998.

GEERTZ, Clifford. A interpretação das culturas. Rio de Janeiro: LTC, 1989.

MARCUSCHI, Luiz Antônio. Gêneros textuais: configuração, dinamicidade e circulação. In: KARWOSKI, Acir; GAYDECZKA, Beatriz; BRITO, Karim S. (Orgs.). Gêneros textuais: reflexões e ensino. Palmas; União da Vitória: Kaygangue, 2005. 
MATTOS, Carmen Lúcia Guimarães de. A abordagem etnográfica na investigação científica. UERJ, 2001.

PINTO-CORREIA, João D. Os géneros da literatura oral tradicional: contributo para a sua classificação. Revista Internacional de Língua Portuguesa. Lisboa, 1993.

ZUMTHOR, Paul. Introdução à poesia oral. São Paulo: Hucitec, 1997. 